\title{
CORPORATE SOCIAL RESPONSIBILITY: THE IMPORTANCE OF THE STAKEHOLDER PERCEPTION
}

\author{
Pavel Adámek \\ Department of Business Economics and Management, School of Business Administration in Karvina, \\ Silesian University in Opava, Univerzitni nam. 1934/3, Karvina 73340, Czech Republic \\ E-mail: adamek@opf.slu.cz
}

\begin{abstract}
The differing views regarding the role of business in society are often presented as being placed within the stakeholder-shareholder debate. Corporate Social Responsibility (CSR) not only sits comfortably with the mantra of maximising shareholder value, sustainable CRS practices enhance shareholder value. The purpose of the current paper is to focus on the strategic implications of stakeholder approach in theoretical background with confrontation in a sample of Czech small and medium-sized enterprises (SME) and large enterprises. Data were collected through personal questionnaires that were subsequently evaluated by dependence on the type of stakeholders and their level of significance. The findings of the research discovered considerable differences between the perception of the role and importance of the various stakeholders. The contribution of this paper derives in application of stakeholder approach in Czech enterprises. They are seen as having an obligation to consider society's long-run needs and wants, which implies that they engage in activities that promote benefits for society.
\end{abstract}

Keywords: Corporate Social Responsibility, stakeholder approach, stakeholder theory, stakeholders, small and medium-sized companies, perception.

JEL Classification: M10; M14.

\section{Introduction}

Corporate Social Responsibility (CSR) and its importance in the strategic approach embedded in corporate strategy gives space for certain benefits that were already confirmed by both corporate practice and carried out research in this area. Problematic definition of CSR and its application has been subjected to a series of technical studies and research from the perspective of an application by the interested parties.

Therefore, the paper is aimed on stakeholder approach and engagement and we examine issues and extend scope as an initial study in the Czech Republic. The purpose of the current paper is to focus on the strategic implications of stakeholder approach in theoretical background with confrontation in a sample of Czech small and medium-sized enterprises (SME) and large companies (overall 200 enterprises).

This article argues that the stakeholder perspective has become something which is inescapable if one wants to discuss and analyse CSR. Stakeholder theory is considered as "a necessary process in the operationalisation of corporate social responsibility, as a complimentary rather than conflicting body of literature" (Matten et al. 2003). The origins of stakeholder theory draw on four key academic fields - i.e. sociology, economics, politics and ethics - and especially the literature on corporate planning, systems theory, corporate social responsibility and organizational theory (Mainandres et al. 2011). Ethical principles are compatible with profit seeking aims, as long-term, sustainable business performance necessitates regard for the organisation's impact on wider society and the environment (Jones 2012).

In general, SMEs are very specific in terms of characteristics, which contribute significantly to the GDP, entrepreneurs contribute to the national budgets in the form of taxes and mandatory contributions, and are significant in terms of employability. This group of companies has certain characteristics that are significant in their impact on the environment, the whole society, but also to local communities. These companies have a minimum rate of use of CSR activities are therefore subject studies focused on theme. There is a lack of consensus about SMEs' familiarity and their perception of CSR (Sen, Cowley 2013).

Firms that invest more in CSR tend to have a stronger reputation for keeping their commitments associated with the implicit contracts, stakeholders of these firms are likely to have stronger incentives to contribute resources and effort to the firm and accept less favourable contracts than stakeholders of low CSR firms (Deng et al. 2013).

Similarly, the main contribution of this article derives primarily from the systematization of some of 
the shortcomings that need overcoming within the framework of stakeholder theory and a research conducted among Czech companies, which reflect theoretical approaches with practical experience of managers. Based on the problematic issues, which are key stakeholders, this paper sets out research agendas aiming to compare the SMEs and large enterprises stakeholder approach.

Hence, we are scheduled issues in this preliminary study based on the literature review to clarify the practical approaches, for the purposes of illustration were determined following research premises:

- There are not the significant differences between the perception of stakeholders between SMEs and large enterprises.

- We can assume that customers are considered as the most important stakeholders (affecting managerial approaches) in all enterprises.

- The companies recognize the influence of the various stakeholders and develop access to them (such as for instance, reporting, stakeholder dialogue, interrelationship etc.).

In order to achieve objective, the paper is structured as follows: firstly, there is presenting an overview of literature review relating to corporate social responsibility and stakeholder approach, highlighting the CSR, stakeholders and stakeholder approach. The article then makes the case for a stakeholder approach to CSR, reviewing its inherent logic and outlining how it has been integrated info recent empirical studies.

The next stage involved the methodology apparat with the description and implementation of the research, followed by interpretation and discussion of the research findings, which provide answers to the above mentioned premise. Finally, in the last section, the conclusions and findings of the preliminary study are discussed.

\section{Corporate social responsibility and stakeholder approach: a literature review}

Today, the various stakeholders in national and international communities expect more responsible use of increased business power. CSR may provide a general framework to structure the responsible use of corporate power and social involvement. These developments have triggered the very real challenge for business managers of deciding how, on a day-to-day practical basis, to operationalise CSR and manage their firm's obligations to their various stakeholders (O'Riordan, Fairbrass 2012).
Stakeholder approaches also facilitate a heightened awareness of CSR, business ethics, and business practices that enable more informed decisions on stakeholder salience (Fassin 2010) and more robust CSR evaluations (Fassin, Buelens 2011). Recently, as Ayuso et al. (2012) observe, stakeholder theory can be connected with the literature of CSR broadly and corporate sustainability within CSR, as it provides a suitable theoretical framework for analyzing the relationship between business and society and to provide direction to the firm's managers (Cordeiro, Tewari 2015). Converting CSR into a business objective could be implemented by the transformation of social and environmental issues into stakeholders interest.

Reflecting this, researchers have begun to explicitly apply stakeholder theory in the natural environment context largely by examining stakeholder pressures on firms to adopt proactive environmental strategies, routines, and innovations that they hope will result in improved environmental performance (Delmas, Toffel 2011). Therefore, we want to determine whether stakeholders are important from the perspective of the management and whether they are toward them implemented specific policies and activities. Concretely, governments, consumers, employees, suppliers and many other groups have shaped the concept of CSR through their expectation that corporations will act responsibly in the conduct of their operations (Bondy et al. 2012).

In terms of definition of CSR, there are dozens of formulations and determination, we are focused on definition from World Business Council on Sustainable Development (WBCSD). Consequently, we synthesised a key rationale as comprising the need for CSR analyses to adopt a systemic approach to balance stakeholder interests, and to incorporate the importance of stakeholders corresponding with CSR. Therefore, in this section we examines some of the key terms and concepts employed in the paper: namely, "corporate social responsibility", "stakeholders", and "stakeholder approach".

\subsection{Corporate social responsibility}

Over the years, the field of CSR has been enriched by numerous such representations that all try to encapsulate the heart and soul of business ethics, corporate citizenship, sustainability, etc. (Pedersen 2010). One of the most prominent examples of a CSR model is undoubtedly Archie B. Carroll's pyramid of CSR that consists of economic, legal, ethical and philanthropic responsibilities (1991). Another popular conceptualisation is Elkington's (1998) triple bottom line (People, Profit, Planet) thinking that has become an im- 
portant inspirational source for much contemporary CSR literature.

Due to the emergence of different approaches may be selected some of them that take into account the impacts of business activities towards society. McAlister et al. (2003) developed a model of corporate citizenship that comprises strategic philosophy, stakeholders, outcomes and corporate social responsibilities; Swanson and Niehoff (2001) invented a model of business citizenship distinguishing between executive stewardship of citizenship processes, employee citizenship behaviour and corporate citizenship responsibilities; Quazi and O'Brien (2000) built a two-dimensional model of CSR that distinguishes between narrow and wide responsibilities and costs and benefits from CSR action; Matten and Crane (2005) conceptualised corporate citizenship by separating between social rights, civil rights and political rights; Meehan et al. (2006) built a CSR model that focused on social and ethical commitments, connections with important partners and behavioural consistency.

In other words, the modelling of CSR almost represents an independent research stream within the business-society field, a research stream that is characterised by a great deal of heterogeneity even though some similarities can be identified (Pedersen 2010). The most of concepts or models of CSR are focused on environmental, economic and social issues and stakeholder approach (interrelationship). This also derives the various definitions of CSR, which are based on implicit models of the firm and its responsibilities toward society (Pedersen 2010). For instance, Dahlsrud (2008) concludes in a recent review of $37 \mathrm{CSR}$ definitions that the concept can be described along five dimensions: stakeholders, social, economic, environmental and voluntariness.

In short, the range of definitions proffered for the term "CSR" appears to arise from the various perceptions held by individuals in relation to the question of business responsibility and obligation (O'Riordan, Fairbrass 2008). These issues, in turn, are derived from a broader debate about the role of business organisations in society (Deresky 2000; Epstein, Roy 2001; Haugh 2003; Maignan et al. 2002; Maignan, Ferrell 2003; Woodward et al. 2001). Finally, another factor that has generated so much discussion is the putative gap between rhetoric and reality concerning CSR policy and practice. In the view of sustainable strategies, CSR has earned more attention over the recent decade due to the benefits it brings to financial, societal, and environmental concerns (Chaabane et al. 2011).

For the purposes of this paper we follow the lead of the World Business Council on Sustainable
Development (WBCSD) and define CSR as an idea that includes the social (e.g. community programmes), the economic (e.g. employment), and the environmental (e.g. waste reduction) aspects of business activity (WBCSD 2002).

In the Czech Republic can be traced followers of the above definitions that were "adjusted" as needed but based on the same assumptions. There is not a clearly defined concept of CSR and its focus. A dominant approach use "3P" approach and triple bottomline consideration of the various activities in the three pillars of the concept, and it's all based on a voluntary approach. It is to the topic of stakeholders and stakeholder approach that this paper now turns.

\subsection{Stakeholders}

The term "stakeholder(s)" is broad ranging in scope. It has been defined as meaning all those individuals and groups with a "critical eye" on corporate actors (Bowmann-Larsen, Wiggen 2004). More neutrally, Freeman (1984) suggests that stakeholders are "groups and individuals who can affect or are affected by, the achievement of an organization's mission". When companies want to reach the peak of its approach to particular problems often portrays itself as the "changer" certain value for their own benefit and interest e.g. in the support of certain interest groups which have political or otherwise significant influence (Fairbrass 2006; O'Riordan, Fairbrass 2008). Consequently, researchers have called for additional empirical evidence of the effects of corporate social performance (Schreck 2011).

Therefore, the main challenge for businesses is the task of identifying to whom they are responsible and how far that responsibility extends (O'Riordan, Fairbrass 2008). The difficulties in managing the relationships from the perspective of business management and stakeholders are issues such as: Firstly, divergent and often conflicting expectations between stakeholders (Bowmann-Larsen, Wiggen 2004; Brammer, Pavelin 2004; Castka et al. 2004; Deresky 2000; Fairbrass 2006; Greenfield 2004; Murray, Vogel 1997). Secondly, contextual complexities (Daniels, Radebaugh 2001) that are further complicated by varying interpretations arising out of different geographical regions and cultures (Castka et al. 2004; Deresky 2000; Epstein, Roy 2001; O'Riordan, Fairbrass 2008; Maignan et al. 2002; Maignan, Ferrell 2003; Woodward et al. 2001) and Thirdly, the challenge of identifying what might be considered to be "best practice" with regard to CSR stakeholder dialogue strategy and then communicating this to stakeholders (Weiss 1998). 
Cumulatively, the expected benefits to organisations that succeed in meeting CSR expectations of key stakeholder groups are increased company revenue and profitability, lower costs, easier access to finance, and a greater capability to innovate (Mason, Simmons 2014). All stakeholder groups seek their willingness to be consistent with legislative measures and obtain benefits from their cooperation and mutual benefit. Also take into account the demeanor and transparent implementation of their needs in strategic approaches CSR.

The discussion immediately indicates which interest groups are for business crucial how they are treated, whether the mechanism of strategic CSR is developed; how are inform its stakeholders (stakeholder dialogue) about targeted activities; how to evaluate these activities (feedback to management or owners); are these findings regularly used to promote the interests of the company or for the benefit of a comprehensive approach to CSR in all areas? Our preliminary study starts to present the general research sample to clarify the Czech approach and specify the core of dissimilarities in approach among SMEs and large enterprises.

\subsection{Stakeholder approach to corporate social responsibility}

The preliminary study in empirical part aims to identify the main stakeholders of enterprises, there is a need to introduce stakeholder approach relating to CSR. While we have defined the responsibilities of a business to society, researchers have been challenged both theoretically and empirically to provide clarity to this construct (Brown, Forster 2013). To define the meaning of stakeholder approach indicate a summary of significant milestones in the development of a theory, which has been linked with approaches to CSR. From its principle it is very timely because it is in the interest of each company to "fully" engaged to their interest groups and maximize their outputs not only in the short term but particularly in the long term business issues. The main reason a corporation adopts CSR is to contribute to a better society and cleaner environment (Velásquez 2012).

Therefore, a promise of stakeholders engagement is that it will allow companies to better understand and respond to the expectations of society. Standards are a way of establisthing a widely applicable benchmark for measuring corporate responsibilities. Access can be existing standards that govern the behavior of organizations to their interest groups and set up communication channels and stakeholder dialogue.
In other words, even when a firm seeks to serve its shareholders as a primary concern, its success in doing so is likely to be affected by other stakeholders (Foster, Jonker 2005; Hawkins 2006). Some even argue that an inclusive stakeholder approach makes commercial sense, allowing the firm to maximize shareholder wealth, while also increasing total value added (Hawkins 2006; Phillips et al. 2003; Wallace 2003).

Cooperation between firms with their stakeholders can bring about the creation of certain values that can strengthen their competitiveness and positive perception of their business. A similar approach was used by Abreu et al. (2005) in their exploration of the CSR experience and practice of enterprises in Portugal. Internally, they also examined workplace practices vis-a-vis employees.

The bulk of the studies encountered in the literature and outlined above fall within the scope of descriptive stakeholder theory, which seeks to outline the views of participants of the mission/objectives of their organization and its actions vis-à-vis different stakeholders (Brickson 2007). There are also flavours in the literature of assessments along the lines of instrumental or normative stakeholder theory. Instrumental stakeholder theory assumes that the corporation is an instrument for wealth creation with CSR conceived as a strategic tool to promote economic objectives (Garriga, Melé 2004). Normative stakeholder theory on the other hand delineates philosophically based moral obligations towards stakeholders (Brickson 2007). While the tenet of stakeholder theory is that all stakeholders matter and that organizations should integrate their responsibilities to the various stakeholder constituencies, this balancing exercise has proven difficult to enact in practice (Galbreath 2006; Vos, Achterkamp 2006).

After the raise of stakeholder theory, in every organization stakeholder engagement became mandatory. The stakeholder strategy combines resources and market-based perspectives with moral ethical values, and that strategy coincides with the CSR strategy (Govindan et al. 2014). The language of stakeholder theory was also easier to grasp by managers/practitioners as most organizations understood and defined obligations and responsibilities vis-a-vis their traditional stakeholders (Clarkson 1995). Therefore, this approach has been used in the empirical part of the paper. We have made a practical reflection of managers and their relationships with stakeholders.

In the Czech Republic there are approaches to CSR, but mostly applied mainly by large enterprises that operate in the international global market. Generally, enterprises are forcing by circumstances, whether legislative (eg. participation in public ten- 
ders) or voluntary (eg. the conditions in the supply chain) to implement specific CSR standards, guidelines of frameworks. These standardization (such as Global Reporting Initiative or OECD Multinational Guidelines) regulates behavior and attitudes of the enterprises towards stakeholders. These activities are often accompanied by developing communication policies and the area is connected with the department of public relations or is created CSR position.

Different approaches are identified by SMEs, which are determined by the scope and size, do not have developed an independent department, because these activities are concentrated in the management of these firms. The situation in the Czech Republic suggests changing conditions, the growing knowledge of the concept of CSR. The enterprises are inspired by "best practices" which are often used as the basis for the implementation of CSR activities. Also, the formation KORP method, which is based on principe London Benchmarking Group is most commonly used for both selfevaluation and for the evaluation of third parties e.g. stakeholders.

Stakeholder approach could be considered as pivotal in understanding the importance of the application of individual activities in all pillars of the CSR concept (economic, environmental and social issues), the companies have to identify key stakeholders and develop appropriate approaches to fullfilment of strategic goals in accordance of sustainable development aspect.

Having outlined in brief some of the basic issues arising from the terms and concepts used in this paper, we now turn to exploring reflection of conception and perception of stakeholders in reality.

\section{Methodology}

The current research investigates the reflection of the company's approach to its stakeholders, whether they are developing a proactive approach and include them in their strategic plans. The research methodology is consistent with descriptive stakeholder theory, which seeks to outline participants' views of what the business organization is doing vis-a-vis its stakeholders (Brickson 2007).

The primary data were collected using a selfadministered paper and pencil questionnaire used a rating method. Respondents (managers of selected companies) assessed the importance of individual indicators on a scale of $\langle 0 ; 5\rangle$.

The research is focused on SMEs and large Czech companies which confirmed to participate in this research. Because it is a preliminary study, so we wanted to achieve the same number of companies: in total has been included in the research of 200 compa- nies (of which 50 micro, 50 small, 50 medium-sized, and large enterprises 50). The questionnaires were distributed, thoroughly explained, self-administrated, recovered and systematized between September and November 2015.

We use weighted mean formula for assessment the degree of influence:

$\overline{\mathrm{x}}=\frac{\sum_{i=1}^{k} x_{i} n_{i}}{n}=\frac{\sum_{i=1}^{k} x_{i} n_{i}}{\sum_{i=1}^{k} n_{i}}=\frac{x_{1} n_{1}+x_{2}+\ldots x_{k} n_{k}}{n_{1}+n_{2}+\ldots n_{k}}$,

where:

$\overline{\mathrm{x}}$ - weighted mean, $x_{1}, x_{2}, x_{k}$ are items given,

$n_{1}, n_{2}, n_{k}$ are frequencies corresponding to the given items.

This procedure was performed for each stakeholder in its responses, which were in the scale of $<0$; 5>; with meaning zero - the company does not build a relationship with that stakeholders, i.e. the stakeholder is not affected by its CSR activities); value 1 mean minimal relationship and value 5 means deeply influence of CSR activities. Calculations were performed by the software program Excel.

\section{Research findings}

Result in Figure 1 convey the results between different categories of SMEs. Here are the most important stakeholder - the customer. The firms while use the CSR activities, there are mostly influenced by customer access, there is clear scope for understanding the importance of stakeholder for each firms.

Among the three major ones still further located at the micro firms are suppliers (value 3.2) and employees (2.68), there is point able that employees of microenterprises are up to third place. It is obvious that for small business is essential to access to this three stakeholders. In the Czech Republic, they are often small businesses dependent on wholesale therefore can be observed greater significance of these stakeholders. The results also showed that the systematic collection and long-term cooperation with suppliers for small businesses in the supply chain is essential. If they lost their major suppliers, they can contain problems with outputs, the service, then this could mean higher costs and dissatisfied customers.

Here is confirmed assumption that many entrepreneurs (owners) often uses the staff as a cheap labour force that can always be replaced. This is a common practice among small businesses in problematic regions with the lower rate of unemployment. These businesses "hold" their key staff and others are using them as "labor" with low labor 
costs, they are treated to them, that can be replaced at any time, which is very discouraging for them. These approaches are common for micro and small businesses.

Results showed that access of small businesses to the government is very "weak" and from longterm approach they criticize the government in the form of bureaucratic measures that burden their business. An approach to government is only understood as a condition of compliance with legislation and contact with the public administration, which is from a business perspective, assessed as inflexible and cumbersome. Only for SMEs results suggest a positive approach (value 2.46), but at a deeper analysis of the results it is clear that this is due to "frequent contact" of these companies with the government through regular communication, reporting, taxation and complex conditions of their activity. The micor and small enterprises do not have such frequent contacts and links with the government.

The minimum rate of evolving CSR activities towards the media (which is surprising, because it can be a suitable issue for building a relationship of communication to reach potential customers) through the appropriate campaigns and events could strengthen their public awareness and their perception of the business community more generally.

This finding is supported by the "lack" of capital and ignorance usability of these stakeholders to strengthen the competitive position and acquisition of new customers. SMEs do not need to disclose their activities through the "media" and do not develop toward them the significant CSR activities.

Within the local community, the small businesses develop only philanthropic and donor activities. It is noteworthy that firms do not develop the relations to its surroundings and in the case of the Czech Republic it is only a form of "visibility" or kind of advertising. The impacts of these approaches are evident when SMEs do not evaluate activiteies, donating is done ad hoc, without a systematic approach.
The exceptions are companies that develop specific projects for the community and trying to create a relationships and create pleasant conditions, not only in their company, but they are beneficial to the general public. These activities were found only in medium-sized companies and large corporations. In terms of large companies they are often set up special funds or foundations that concentrate project aimed at local communities (e.g. corporate social events, open days, cleaning nature, special educational events for children and parents, the creation of social benefits and programs, construction of kindergartens etc.). Overall, we found that approach to local communities is based on the size of the enterprise.

Large differences (Table 1) are also identified by the "owners" who are important from the perspective of small enterprises, which were represented at the second place after the customers. Other types of enterprises do not develop such a concentration on these interest group. In more detail, it is clear that these firms have been identified relating to merging role of manager and company owner.

The results suggest strengthening the role role of the suppliers in respect of whom are already applied to certain behavioral aspects of CSR. This is due to very frequent interconnectedness in the subcontracting chain and condition to exploite the certain quality standards not only products, but all processes. For companies stems from the strengthening of these approaches for establishing cooperation and building a reputation in the market.

Results (see Table 1) show us the "juicy" reality, which actualities indicate that with the size of the company (according to criteria SME) increases the degree of influence of the stakeholders. Here the question arises, why this is, but we believe that it is in compliance e.g. a preferable management of the company, access to capital, more educated and conscious employees, etc.

Table 1. Stakeholder's order of importance in all categories (values in weighted mean) (Source: own research)

\begin{tabular}{l|c|c|c|c|c|c}
\hline \multicolumn{1}{c|}{ Type of stakeholder } & Micro & Small & Medium & Total SMEs & Large & Total \\
\hline employees & 2,680 & 2,600 & 3,380 & 2,887 & $\mathbf{4 , 1 8 0}$ & 3,210 \\
\hline customers & $\mathbf{3 , 5 0 0}$ & $\mathbf{3 , 4 0 0}$ & $\mathbf{3 , 4 4 0}$ & $\mathbf{3 , 4 4 7}$ & 3,900 & $\mathbf{3 , 5 6 0}$ \\
\hline suppliers & 3,200 & 2,320 & 3,000 & 2,760 & 3,620 & 2,975 \\
\hline owners & 2,580 & 3,040 & 2,600 & 2,740 & 3,460 & 2,920 \\
\hline competition & 2,500 & 2,460 & 1,940 & 2,300 & 3,140 & 2,510 \\
\hline government & 1,760 & 2,040 & 2,460 & 2,087 & 2,960 & 2,305 \\
\hline media & 2,060 & 2,160 & 2,300 & 2,173 & 3,400 & 2,480 \\
\hline local communities & 1,800 & 1,800 & 2,100 & 1,900 & 3,100 & 2,200 \\
\hline
\end{tabular}


When comparing the results (Fig. 2) with access of large enterprises, so here we find already very significant differences in values especially when striking interested in these companies precisely to stakehoder type: employees (4.18), customers (3.9) or suppliers (3.6). The owners are up to fourth in the level of importance of media here is space for higher commitment management of companies toward their owners (shareholders).

For less relevant stakeholders is considered government (2.96), local communities (3.1), and medium (3.4). Also noteworthy competition that occurs among all groups in half of between selected stakeholders (nowhere did not deviate significantly). Large companies have more than one degree higher utilization activities to its stakeholders and also had much more proactive approach (an example can be value for customers and employees). Over the last 5 years can be seen a significant shift in the perception of large companies there is almost standard that they implement CSR into their business objectives and CSR managers develop specific activities to all stakeholders. Positive results in comparison with SMEs are identified in all interest groups and community area plays a greater significance. If we summarize the results, the customers and employees are the most important and companies are developing a specific "stakeholder approach" for a specific group of stakeholders.

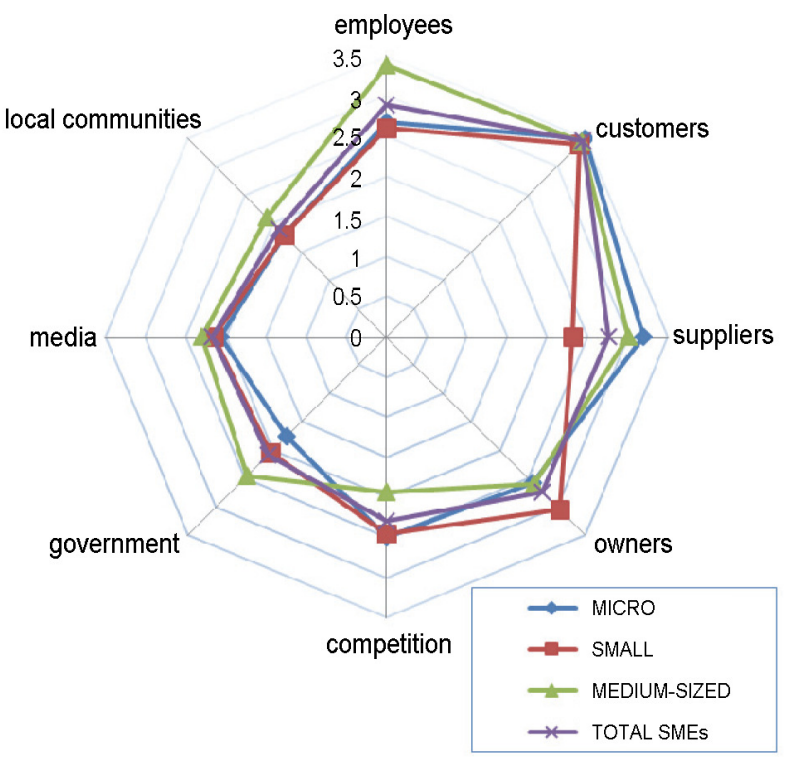

Fig. 1. The importance of stakeholders: comparison between micro, small and medium-sized enterprises (Source: own research)

Overall, large enterprises have already developed a strategic approach to its stakeholders and developing systematic activities that fall within the strategic management of CSR, compared with
SMEs. Observed values of maximum interest in the impact on the stakeholders reflecting the fact that they are an order of magnitude higher, and no enterprises also stated that it would ignore any stakeholder which we set.

Results indicate (Fig. 2) that the dominant stakeholders are customers (3.56), employees (3.21), suppliers (2.975) and owners (2.92). Conversely, less significant are considered local communities (2.2) and government (2.305). It is astonishing that companies do not pain attention to their environment in which it operates. There is field for future systematic change, because each company carries out its activities e.g. in a given locality, culture, mentality, in the village, in the region and their activities are affected residents. In the Czech Republic for a long growing resentment towards the government, and the results showed that the company fulfils only the "letter of the law" and do not developed extra CSR activities towards the state apparatus and public administration.

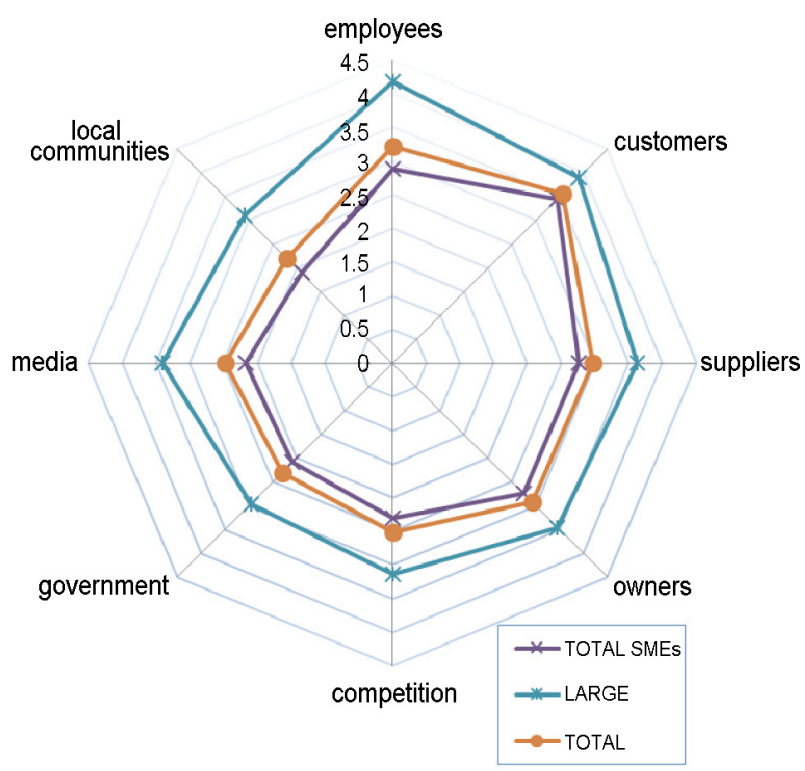

Fig. 2. The importance of stakeholders: comparison between SMEs, large and total enterprises

(Source: own research)

If companies are interested to its stakeholders and seeks to influence its activities just to them, so it was subject to the following findings (Fig. 3). Results proven a huge difference between proactive approach by large companies and SMEs, where more than half of large companies actively communicates with their stakeholders and implements the current findings into their long-term plans and strategies, and on the other hand, SMEs, where more than half of these businesses at all is not active policy towards the stakeholders (will understand that there are, but no incentive for interaction). 


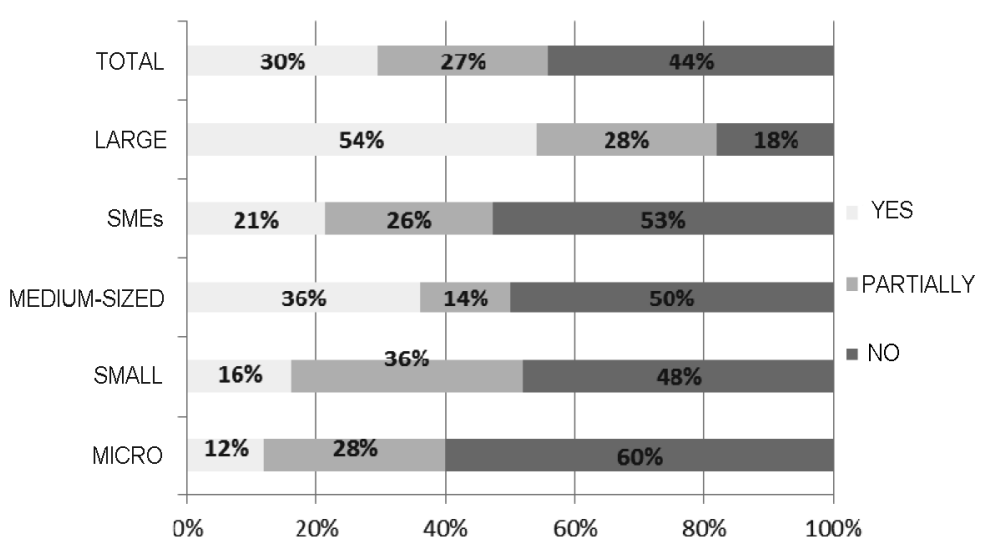

Fig. 3. Existence (or absence) of an active approach to stakeholders

(Source: own research)

The dominant approach is in the "micro" businesses that only $12 \%$ of cases actively act towards its stakeholders and only $18 \%$ of large companies not acting at all to their interest groups. The results clearly show that small companies do not develop CSR activities, it can be assumed that this is due to their unwillingness to do certain activities beyond the scope and approach to the concept is perceived as a sort of tool in addition wchich may not be implemented. In the Czech Republic fail a role of government or government organizations in promoting these ideas with an emphasis on SMEs. This evokes us additional areas for subsequent detection of context and factors that determine these approaches in subsequent research.

For a detailed view, the apparent shift in perspective according to a size of the enterprises it can be monitored. The importance of stakeholder engagement and proactive activities are related to the size of the company. Awareness of key stakeholders is conditional on their meaning and the majors (equity) is a trend (in large and multinational enterprises) that is already established position in the organizational structure (CSR manager), which is closely associated with public relations and is responsible for implementing socially responsible activities and communication with stakeholders. Todays, the trend when large companies are already recognized and are certified by the systems in the field of CSR and more participation in prestigious competitions. These positive trends are beginning to penetrate the "medium-sized" companies that see a potential in implementing of CSR activities that can bring many benefits in the form of long-term relationships with customers (higher sales), building a positive public relation in the community, cost savings, eg. in environmental part and many others. These benefits are becoming extremely important and the positive shift in SME sector is registered.

\section{Conclusions}

The paper's systemic approach links to filling the gap of reflection between theoretical stakeholder approach and confrontation findings in a reality of Czech companies, which were compared in area of SMEs and large enterprises. Large firms operating in Czech defined CSR along the four main stakeholders: employees, customers, suppliers and owners. SMEs tend to define CSR as a conduction business in particular contributing to their customers, employees and suppliers. We contend that stakeholder groups compare CSR outcomes with their expectations, and that these assessments have attitudinal and behavioural implications. Organisational obligations in relation to CSR continue via an acceptance of the need to have feedback to stakeholders on CSR outcomes, together with a commitment to remain in dialogue with them on actions that the organisation may take as a result.

This preliminary study was based on a sample of enterprises, but has produced more nuanced insights into SMEs and large enterprises social responsibility, and the applicability of stakeholder approach in reality. The empirical findings reported in this paper are generally consistent with the literature, and suggest that are "reserves" in Czech companies in approaches towards its stakeholders, especially in the SME sector, particularly in micro enterprises. The volume and diversity of CSR activities was positively correlated with size.

In summary, we postulate the answers to the premises which are based on the research results, it is clear: there is essential differences between the perception of stakeholders in SMEs and large enterprises; customers are considered as the most important stakeholders (affecting managerial approaches) in all enterprises (except for large enterprises there are dominant employees) and SMEs not apply to the necessary extent to their stake- 
holders, more than half of large enterprises use proactive approach to their stakeholders (such as for instance, reporting, stakeholder dialogue, interrelationship etc.).

There is a need for more research along these lines within the context of a stakeholder approach. The challenge is thus to use some of the questions and theoretical/empirical insights derived here to serve as catalysts for future. That said, we suggest further investigation on the research problem in different areas (systematically in all regions in the Czech Republic and as well as in international comparison), involving a larger sample size and using different methodologies to validate research findings. Further research is also required to explore the importance of each type of social capital that enterprises multiply through different stakeholders.

\section{Acknowledgements}

This paper was supported by the Ministry of Education, Youth and Sports within the Institutional Support for Long-term Development of a Research Organization in 2016.

\section{References}

Abreu, R.; David, F.; Crowther, D. 2005. Corporate social responsibility in Portugal empirical evidence of corporate behaviour, Corporate Governance 5(5): 3-18. http://dx.doi.org/10.1108/14720700510630013

Ayuso, S.; Rodriguez, M. A.; Garcia-Castro, R.; Arino, M. A. 2012. Maximizing stakeholders' interests: an empirical analysis of the stakeholder approach to corporate governance, Business and Society 53(3): 414-439.

http://dx.doi.org/10.1177/0007650311433122

Bondy, K.; Moon, J.; Matten, D. 2012. An institution of corporate social responsibility in multi-national corporations (MNCs): form and implications, Journal of Business Ethics 111: 281-299. http://dx.doi.org/10.1007/s10551-012-1208-7

Bowmann-Larsen, L.; Wiggen, O. 2004. Responsibility in world business: managing harmful side-effects of corporate activity. USA: United Nations University Press.

Brammer, S.; Pavelin, S. 2004. Building a good reputation, European Management Journal 22(6): 704 713. http://dx.doi.org/10.1016/j.emj.2004.09.033

Brown, J. A.; Forster, R. 2013. CSR and stakeholder theory: a tale of Adam Smith, Journal of Business Ethics 112: 301-312. http://dx.doi.org/10.1007/s10551-012-1251-4

Brickson, S. 2007. Organizational identity orientation: the genesis of the role of the firm and distinct forms of social value, Academy of Management Review 32(3): 864-888.

http://dx.doi.org/10.5465/AMR.2007.25275679

Castka, P., et al. 2004. How can SMEs effectively implement the CSR agenda? A UK case study perspective, Corporate Social Responsibility and Environmental Management 11: 140-149. http://dx.doi.org/10.1002/csr.62

Carroll, A. B. 1991. The pyramid of corporate social responsibility: toward a moral management of organizational stakeholders, Business Horizons 34(4): 39-48.

http://dx.doi.org/10.1016/0007-6813(91)90005-G

Clarkson, M. 1995. A stakeholder framework for analysing and evaluating corporate social performance, Academy of Management Review 20(1): 92-117.

Cordeiro, J. J.; Tewari, M. 2015. Firms characteristics, industry context, and investor reactions to environmental CSR: a stakeholder theory approach, Journal of Business Ethics 130: 833-849. http://dx.doi.org/10.1007/s10551-014-2115-x

Dahlsrud, A. 2008. How corporate social responsibility is defined: an analysis of 37 definitions, Corporate Social Responsibility and Environmental Management 15(1): 1-13. http://dx.doi.org/10.1002/csr.132

Daniels, J.; Radebaugh, L. 2001. International business: environments and operations. New Jersey: Prentice Hall.

Delmas, M.; Toffel, M. W. 2011. Institutional pressures and organizational characteristics: Implications for environmental strategy, in Oxford handbook of business and the Environment. Oxford: Oxford University Press.

http://dx.doi.org/10.1093/oxfordhb/978019958445 1.003 .0013

Deng, X.; Kang, J.; Low, B. S. 2013. Corporate social responsibility and stakeholder value maximization: evidence from mergers, Journal of Financial Economics 110: 87-109. http://dx.doi.org/10.1016/j.jfineco.2013.04.014

Deresky, H. 2000. International management: managing across boarders and cultures. New Jersey: Prentice Hall.

Elkington, J. 1998. Cannibals with Forks. Canada: New Society Publishers.

Epstein, M.; Roy, M. 2001. Sustainability in action: identifying and measuring the key performance drivers, Long Range Planning 34: 585-604. http://dx.doi.org/10.1016/S0024-6301(01)00084-X

Fairbrass, J. 2006. UK Businesses and CSR policy: shaping the debate in the EU. Working Paper $06 / 31$. School of Management, University of Bradford.

Fassin, Y. 2010. A dynamic perspective on Freeman's stakeholder model, Journal of Business Ethics 96: 7-9. http://dx.doi.org/10.1007/s10551-011-0942-6 
Fassin, Y.; Buelens, M. 2011. The hypocrisy-sincerity continuum of corporate communication and decision making: a model of corporate social responsibility and business ethics practices, Management Decision 49(4): 586-600. http://dx.doi.org/10.1108/00251741111126503

Foster, D.; Jonker, J. 2005. Stakeholder relationships: the dialogue of engagement, Corporate Governance 5(5): 51-57. http://dx.doi.org/10.1108/14720700510630059

Freeman, E. R. 1984. Strategic management: a stakeholder approach. Boston: Pitman.

Galbreath, J. 2006. Does primary stakeholder management positively affect the bottom line?, Management Decision 44(9): 1106-1121. http://dx.doi.org/10.1108/00251740610690649

Garriga, E.; Melé, D. 2004. Corporate social responsibility theories: mapping the territory, Journal of Business Ethics 53: 51-71. http://dx.doi.org/10.1023/B:BUSI.0000039399.905 87.34

Govindan, K.; Kannan, D.; Shankar, K. M. 2014. Ealuating the drivers of corporate social Responsibility in the mining industry with multi-criteria approach: a multi-stakeholder perspective, Journal of Cleaner Production 84: 214-232. http://dx.doi.org/10.1016/j.jclepro.2013.12.065

Greenfield, W. M. 2004. In the name of corporate social responsibility, Business Horizons 47(1): 19-28. http://dx.doi.org/10.1016/j.bushor.2003.11.004

Haugh, R. 2003. Getting the attention of Big Pharma, Hospitals and Health Networks 77(10): 44.

Hawkins, D. 2006. Corporate social responsibility: balancing tomorrow's sustainability and today's profitability. New York: Palgrave Macmillan. http://dx.doi.org/10.1057/9780230625815

Chaabane, A.; Ramudhin, A.; Paquet, M. 2011. Designing supply chains with sustainability considerations, Production Planning and Control 22(8): 727-741.

http://dx.doi.org/10.1080/09537287.2010.543554

Quazi, A. M.; O'Brien, D. 2000. an empirical test of a cross-national model of corporate social responsibility, Journal of Business Ethics 25(1): 33-51. http://dx.doi.org/10.1023/A:1006305111122.

Jones, D. 2012. Who cares wins: why good business is better business. Financial Times Series. London: Financial Times.

Maignan, I.; Ferrell, O. 2003. Nature of corporate responsibilities: perspectives from American, French, and German consumers, Journal of Business Research 56: 55-67. http://dx.doi.org/10.1016/S0148-2963(01)00222-3

Maignan, I., et al. 2002. Managing socially responsible buying: how to integrate non-economic criteria into the purchasing process, European Management Journal 20(6): 641-648. http://dx.doi.org/10.1016/S0263-2373(02)00115-9
Mainandres, E. W.; Alves, H.; Raposo, M. 2011. Stakeholder theory: issues to resolve, Management Decision 49(2): 226-252.

http://dx.doi.org/10.1108/00251741111109133

Mason, C.; Simmons, J. 2014. Embedding corporate social responsibility in corporate governance: a stakeholder systems approach, Journal of Business Ethics 119: 77-86.

http://dx.doi.org/10.1007/s10551-012-1615-9

Matten, D.; Crane, A. 2005. Corporate citizenship: toward an extended theoretical conceptualization, Academy of Management Review 30(1): 166-179. http://dx.doi.org/10.5465/AMR.2005.15281448

Matten, D.; Crane, A.; Chapple, W. 2003. Behind the mask: revealing the true face of corporate citizenship, Journal of Business Ethics 45: 109-120. http://dx.doi.org/10.1023/A:1024128730308

McAlister, D. T.; Ferrell, O. C.; Ferrell, L. 2003. Business and society: a strategic approach to corporate citizenship. Boston: Houghton Mifflin Company.

Meehan, J.; Meehan, K.; Richards, A. 2006. Corporate social responsibility: the 3C-SR model, International Journal of Social Economics 33(5/6): 386398.

http://dx.doi.org/10.1108/03068290610660661

Murray, K. B.; Vogel, C. M. 1997. Using a hierarchy-of effects approach to gauge the effectiveness of corporate social responsibility to generate goodwill toward the firm: financial versus non financial impacts, Journal of Business Research 38: 141-159. http://dx.doi.org/10.1016/S0148-2963(96)00061-6

O'Riordan, L.; Fairbrass, J. 2012. Managing CSR stakeholder engagement: a new conceptual framework, in Paper presented at the 11th World Congress of Congress of the International Federation of Scholarly Associations of Management (IFSAM), 26-29 June 2012, University of Limerick, Ireland.

O'Riordan, L.; Fairbrass, J. 2008. Corporate Social Responsibility (CSR): models and theories in stakeholder dialogue, Journal of Business Ethics 83: $745-758$. http://dx.doi.org/10.1007/s10551-008-9662-y

Pedersen, E. R. 2010. Modelling CSR: how managers understand the responsibilities of business towards society, Journal of Business Ethics 91: 155-166. http://dx.doi.org/10.1007/s10551-009-0078-0

Phillips, R.; Freeman, E.; Wicks, C. 2003. What stakeholder theory is no, Business Ethics Quarterly 13(4): 479-502. http://dx.doi.org/10.5840/beq200313434

Sen, S.; Cowley, J. 2013. The relevance of stakeholder theory and social capital theory in the context of CSR in SMEs: an Australian perspective, Journal of Business Ethics 118: 413-427. http://dx.doi.org/10.1007/s10551-012-1598-6 
Schreck, P. 2011. Reviewing the business case for corporate social responsibility: new evidence and analysis, Journal of Business Ethics 103(2): 167188. http://dx.doi.org/10.1007/s10551-011-0867-0

Swanson, D.; Niehoff, B. P. 2001. Business citizenship outside and inside organisations, in J. Andriof, M. McIntosh (Eds.). Perspectives on corporate citizenship. Sheffield: Greenleaf Publishing Limited, 104-116. http://dx.doi.org/10.9774/GLEAF.978-1909493-19-3 8

Velásquez, T. A. 2012. The science of corporate social responsibility (CSR): contamination and conflict in a mining project in the southern Ecuadorian Andes, Resources Policy 37(2): 233-240. http://dx.doi.org/10.1016/j.resourpol.2011.10.002

Vos, J.; Achterkamp, M. 2006. Stakeholder identification in innovation projects: going beyond classification, European Journal of Innovation Management 9(2): 161-178.

http://dx.doi.org/10.1108/14601060610663550
Wallace, S. 2003. Value maximization and stakeholder theory: compatible or not?, Journal of Applied Corporate Finance 15(3): 120-127.

http://dx.doi.org/10.1111/j.1745-6622.2003.tb00466.x

WBCSD. 2002. The business case for sustainable development: making a difference towards the Johannesburg Summit 2002 and beyond. World Business Council for Sustainable Development, Geneva, Switzerland.

Weiss, J. W. 1998. Business ethics: a stakeholder and issues management approach. Forth Worth: Dryden Press.

Woodward, D., et al. 2001. Some evidence on executives. Views of corporate social responsibility, British Accounting Review 33: 357-397. http://dx.doi.org/10.1006/bare.2001.0165 